\title{
Reading Human Rights Through Emmanuel Levinas's Theory of Ethics and Existentialism
}

\author{
$1^{\text {st }}$ Sulfiah \\ Department of Philosophy, Faculty of \\ Humanities \\ University of Indonesia \\ Depok, Indonesia \\ sulfiah999@gmail.com
}

\author{
$2^{\text {nd }}$ James Farlow Mendrofa* \\ Department of Philosophy, Faculty of \\ Humanities \\ University of Indonesia \\ Depok, Indonesia \\ jamesfmendrofa@gmail.com
}

\begin{abstract}
The Universal Declaration of Human Rights (hereinafter referred to as UDHR) is meant to guarantee equal rights for everyone, including women and minorities. While the UDHR stipulates protection from racial discrimination and other issues of social inequality, human rights violations are found everywhere. The author found that the issue of human rights is usually focused on "right-holding." As a result, the claim of protecting one's human rights can be used to justify selfish actions. This issue is exacerbated by the development of communal culture throughout Asian society, including Indonesia. A hostile majority group may declare they are exercising their human rights even if their actions affect minority groups in negative ways. Majority groups, therefore, may declare that their actions, rather than violating minority rights, are carrying out their own rights, and thus the minority group should be considered "wrong" and even deserving of punishment. This article uses the refutation method by describing deficiencies in the understanding of human rights which emphasize the right to hold. "Encountering with the other's face," a theory by Levinas, has the potential to produce a new understanding: the basis of human rights is the obligation of each individual to look after "others." One cannot escape this responsibility, even if it is seen as a burden, for it provides meaning to one's life.
\end{abstract}

Keywords-Human Rights, Social Inequalities, Individualism, Collectivism, Levinas

\section{INTRODUCTION}

Human rights, as stated in the International Covenant on Civil and Political Rights, "derive from the inherent dignity of the human person" [1]. Thus, human rights are understood as views that uphold the dignity of an individual solely because they are human. Humans have inherent values that cannot be revoked; they were born with those values, which make up the dignity of each individual. From this understanding, it can be seen how the notion of human rights emphasizes the individual, or "right-holding."

Jack Donnelly said, regarding rights, "truth" and righteousness are two different things. When talking about "truth," the question is, "is it good if I do this?" However, when talking about rights, we do not ask, "is it good if I do this?" Instead, we talk about the rights that we hold (as in, "I have the right to..." [1]). From these two explanations from Donnelly, it is clear how human rights are understood as inherent values with an emphasis on "I," or right-holding.

Donnelly [1] also stated "Rights are not just one type of social or moral goal co-equal with others; rather, in ordinary circumstances, rights have prima facie priority over utilitarian calculations or considerations of social policy. In fact, one of the basic purposes of rights would seem to be to insulate right-holders from claims based on such principles, which otherwise would be not only appropriate but decisive reasons for political and even individual action" [1] From all the explanations above, it can be seen that the purpose of Human rights is more than just social regulation, more than morality acts, but to protect "I" from those in power, and from policies that only concern certain parties. Utilitarianism holds that "the most good is the most happiness." Therefore, if the interests of one or two people are not accommodated, that is not a problem, as long as a greater number of interests are accommodated. Human rights protect "I" from policies like this, regardless of their intent. However, "I" must not be treated arbitrarily, because "I" have inherent rights and dignity. "I" have rights that their interests be accommodated. Donnelly said, "it is essential to rights that they have this special status of taking priority over all but the most pressing non-rights demands and interests" [1]

However, problems arise when "I" meet with other "I." For example, we shall call the first "I" A, and the second "I" B. A desperately needs money for their survival, while B has money. Does this condition give A the right to B's money? Donnelly noted that $\mathrm{B}$ could have a moral obligation to give or donate money to A, but A had absolutely no rights to B's money, and thus had absolutely no right to ask for B's money.

Based on Donnelly's answer, the author ultimately realized the weaknesses of the human rights argument based on individual rights with the emphasis on "I have the right to." A and B are individuals, and as such both are "I." Based on Donnelly's understanding of human rights, both A and B have the right to defend their lives. A may say "I have the right to live, so give me your money, because I have to live," while B might say, "I have the right to defend my life, which includes refusing to give my money to anyone." Chaos results if individuals only shout to one another, "this is my right!"

The above explains a type of phenomenon that has occurred in human rights violation cases. Human rights are often only discussed and considered by the "I" who experienced the violations. The "I" who do not experience violations of human rights may find them irrelevant-or perhaps consider the issue of human rights itself unimportant. People may only defend human rights when they experience human rights violations themselves. When someone in the majority sees unusual behavior that might be considered bad behavior, they may not defend the human rights of those who commit the unusual behavior. The argument is that "I" have the right to feel comfortable and safe from the unusual behavior of "the other," thus "the 
other's" rights may be revoked. In short, the human rights of individuals or minority groups who display unusual behavior may be violated because they are considered as threatening to the human rights of a greater number of people around them.

There are many shortcomings in understanding human rights as individual writings: HAM becomes a dogma whose justification can be very unclear; its argument is circular and tautological. Human rights may be widely rejected due to the judgment of human rights as an individualist understanding, primarily by the Asian people. This is clearly seen in the emergence of the Asian Values Debate which has been discussed by Amartya Sen. The Asian Values Debate proposed that human rights ideas cannot be applied in Asia because they are considered Western values that prioritize individual interests, whereas Asian nations prioritize collectivism [2].

What kind of framework is most appropriate to use in understanding human rights? Based on the shortcomings of the understanding of human rights as emphasizing individual freedom as described by the writer above, this writer proposes a thesis that the most appropriate framework for understanding human rights is as follows: Human rights are based on an inherent sense of responsibility that each individual has for others. This feeling of responsibility can motivate individuals to realize the freedom of marginalized groups. Therefore, it is not individual freedom or individual rights that form the basis of human rights, but rather a sense of responsibility for others. The feeling of responsibility itself is not individual freedom, but a feeling that continues to determine each individual's actions while being aware of and caring for the other. My thesis is corroborated by French philosopher Emmanuel Levinas. The main focus of his theory on ethics and existentialism is that "I" have a responsibility to the others. The author does not find any paper that tries to read human rights through Levinas's theory, perhaps because human rights have long been considered as closer to law or politics than to existentialism and ethics. However, the author sees that human rights are motivated by ethical actions and feelings of responsibility for the other and/or marginalized groups, and there is a responsibility to protect individuals from greater powers. Thus, the author offers a new way of reading human rights through the lens of Emmanuel Levinas's theory. Levinas deftly explained how the feelings of responsibility arise; his explanation will be explored in the discussion section.

\section{METHOD}

The author makes a conceptual distinction between understanding human rights based on individual freedom and understanding human rights as responsibility. The distinction may seem simple, but the implications are extraordinary. The understanding that the writer offers is like carrying out a Kopernikan revolution in human rights. The implication is that human rights are innate, based not on the freedom to follow one's own interests or concerns, but on the responsibility to love others. Human rights must be innate if they serve as a sense of responsibility for others. This responsibility is a feeling that continues to determine each individual's actions to be aware of and care for the other. This responsibility may certainly carry a burden, but there is nothing one can do other than fulfill that responsibility.
The author also uses the refutation method. The author rejects the conventional understanding of mainstream human rights by showing the deficiencies in understanding human rights as relating only to individuals.

\section{Results and Discussion}

Jeremy Bentham's essay "Anarchical Fallacies" criticized the French Declaration and questioned the idea of natural rights. Bentham said that the existence of natural rights could not be confirmed and verified. He saw an anarchical fallacy in the French Declaration, about which he declared: "[it] sows the seeds of anarchy broad-cast." He charged that it supported "the rights of anarchy-the order of chaos" because of a hidden message that stated, "O people, hold tight your rights, and if even a few of your rights are injured, then rebellion is not only your rights, but the noblest duty for you!" [3]. For Bentham, this was a very confusing idea; rights cannot be violated, but if they are violated, riots will be caused-obviously, this could lead to violations of other rights. This led Bentham to mock the idea that "rights cannot be violated!'[3]. Bentham's criticism was due to his concept of human rights as an individual's understanding, which means defending your own rights also defends the rights of others.

Bentham's criticism is reasonable; the argument that individual rights are the basis of human rights can be seen in the preamble and articles of the Universal Declaration of Human rights (hereinafter abbreviated to UDHR) which emphasize that each individual has certain rights. The following is a list of several articles of the UDHR:

1. Article 3: Everyone has the right to life, liberty and the security of person

2. Article 4: No one shall be held in slavery or servitude; slavery and the slave trade shall be prohibited in all their forms

3. Article 5: No one shall be subjected to torture or to cruel, inhuman or degrading treatment or punishment

4. Article 6: Everyone has the right to recognition everywhere as a person before the law [4]

This description in the UDHR creates an understanding that basic human rights are individual interests. However, placing individual interests at the center of human rights will not achieve the actual realization of those rights. The questions often forgotten or missed when discussing human rights include: "What is the purpose of human rights?" and "Why must there be human rights?" When we recall, the background for the UDHR was anger and concern at seeing thousands of lives being victimized during the events of World War II. Its aim was to protect those who are weak from those who have power, and create peace for all of humanity. Thus, these goals must be the main focus. However, by understanding human rights only on the basis of individual interests, there is the risk of the individual being concerned only about their own rights to the exclusion of the rights of others - and of the human race as a whole. People might only defend human rights when certain human rights violations occur in their own lives, and not do so if 
they are not among those who have experienced human rights violations.

Based on the explanation above, it appears that shortcomings will occur if we consider the basis of human rights to be limited to personal interests. Therefore, the author offer a way out, namely, a new way of thinking of human rights as "the obligation of each individual to protect the others." The definition embraced by the UDHR states, "no one is allowed to kill other people, on the contrary each individual is responsible for the lives of the others," and "no one is allowed to enslave another people, on the contrary each individual is required to protect the others in order not to be slaves by any party."

Levinas explained that the individual, or "I," is always selfish; they are in a state of "totality." Levinas explained that the "I" who identify themselves as different and separate from the other cause two states: "totality" and "infinite." Totality is the attitude of "I" that makes themself the center of everything. "I" see the other only in terms of their "relative otherness." With this view, the others will only be seen as fulfillments of needs. The "I" made the other into his understanding: the other is defined to the extent that "I" want. In short, the other is reduced by "I." In the end, "I" will exploit the other: "they are at his disposal for his enjoyment and possession. Satisfying the needs of the self, the subject, means and involving reducing the other to the self. It also implies an appropriation and exploitation of the other and reality by the self" [5].

This totality occurs because "I" approach the other with subject-object relations. Since "I" is the subject and the other is the object, all qualities of the others are limited to the understanding of the subject, by use of the "objective gaze." "...to approach the other in this way is no other than to circumscribe his being in the sum of determinate qualities that are open to the vision of a viewer, a spectator or an observer...it means that his whole being is exhausted in the totality of these qualities. But to say this is no other than to reduce his status to that of an object" [5]. Levinas uses the word "vision" to refer to the "I" perspective of the other. The knowledge gained from this "vision" is only a reduction; it does not really describe the other.

The other will only be meaningful as long as they are seen to have certain qualities that enable them to become objects that can manifest pleasure. If this attitude is applied, the situation violates what Levinas explained about how the subject, or "I," was formed. Levinas said "I" was aware of the other's differences, and acknowledged and allowed those differences, which meant that the other must always be something other than "I." This state of totality is just the opposite, in that it only means that the other can be used as a tool: owned, controlled, dominated, manipulated, and exploited by "I."

However, after "I" encounters "the other," "I" is no longer selfish. Contrary to the state of totality, Levinas says there are infinite conditions; this infinite state means acknowledging all the other's differences and separations. Because the other are separate, they are outside "I," so their knowledge will never be controlled and known by "I." (This is the meaning of infinity.) To know what the other really is, "I" does not use only "vision," that is to say, only by observing with the eye. There is a dimension of "interiority" that goes beyond things or qualities we can observe. Therefore, the other cannot be fully understood.

Although the other cannot know "I" fully, there is an approach that can be taken without falling into totality. This approach will not make the relationship between "I" and the other into a subject-object relationship, but instead into a subject-subject relationship. In this way, "I" won't exploit the other. The process of approaching the other involves the experiencing of a "face-to-face encounter." The other manifests itself as a face-facing directly to "I." This manifestation, or self-disclosure, is called "the epiphany of the face" [5].

The "I" who encounter with "the other face" and "the ace of the other" will reveal itself to "I" to experience it as a whole. The word "experience the other" is used to describe how "I" accept and know "the other." However, the word "know" is not suitable for describing the relationship between "I" and the "others," because the word "know," according to Levinas, means to master, grip, or oppress [5]. Experiencing the others does not need to be taken from a certain context; the other's face engulfs everything in themselves as it really is. This revelation occurs without attributes, without form and without any category [5]. "I" remain aware of his separation from "the other." It is only through recognizing all separations (the ways "the other" differs from "I") that "I" is able to experience "the other." "I" see the body separated from them, and "I" experience the awareness that the body can be hurt, feel pain, and suffer: "...that body can experience cold and can experience shame because of his nakedness" [6].

This view becomes very relevant in human rights. As the authors previously explained, the UDHR was created out of concern for the thousands of victims of World War II. This concern is a form of awareness - the "I" who finally experiences an encounter with "the face of the other." Concern raises a sense of responsibility; responsibility means that all people of the world must respect everyone. However, this concept may be confused with the argument that each individual has inherent rights - and that is the reason we must protect human rights. In fact, we can explain by stating that everyone has an obligation to protect "the other" without having to involve ideas about natural human rights, inherent human rights, God-given rights, etc; thus the resulting concept of human rights will be more readily accepted.

Human rights are also understood as reciprocal relationships. Reciprocal means that we care about other people with the hope that other people will care about us. Emmanuel Levinas said that there is a true relationship between humans, and that a true relationship is not a reciprocal relationship. The author adopts Levinas's theory of true relationships. Why can't human rights be reciprocal? Because human rights are born of empathy: feelings that say something is wrong when witnessing harm to other people. This means that human rights are born from ethical feelings. In contrast, the belief that human rights come only from a place of wanting to protect our own human rights does not stem from ethical feelings. It is an asymmetrical relationship when "I" experience an encounter with the "face of the other," which in turn reveals itself to "I" so that "I" is able to experience it in full [5]. 
Due to this manifestation of and revelation about "the other," "I" will feel a responsibility towards "the other." This responsibility is clearly a burden on "I," but "I" can do nothing but accept and carry out that responsibility. This happens because "the other" reveals themselves directly to "I," "I" realize separation from "the other" by witnessing that the body of the "other" can feel pain. The responsibility of "I" to the others, according to Emmanuel Levinas, is not the desire to help that arises from feelings of sympathy or empathy, but a responsibility that has been embedded in humans long before consciousness. In other words, responsibility for others is a priori knowledge. This feeling of responsibility does not originate in "I." On the contrary, this feeling originates from outside the "I," which has ironically been the case throughout the history of human life [5]. Before humans are aware of themselves, responsibility for others already exists. Levinas referred to this period as the past that can no longer be remembered (immemorable past). In my opinion, this is in line with the phenomenology of Martin Heidegger, who felt that consciousness is always historic. Heidegger called this in-der-welt-sein, which can be translated as "in the shared world." Humans always precede themselves; there is a consciousness rooted in history in which there is both knowledge and mystery about the future (a pre-ontological understanding of being).

My relationship with others, in Levinas's view, is always one of extreme altruism. I sacrifice something I have for someone else's life. However, in Levinas's ethics, not only is there no longer egoism, but we are even "imprisoned" by the presence of others. When there are other people in front of us, we already hold a responsibility to them; the comfort of our individualism is disturbed and the way we live and exist is questioned. Ethics is not something that needs further discussion; ethical action does not require intent on the basis of empathy. It is unavoidable. For Levinas, to be an ethical human being is to serve other human beings with complete surrender. This is similar to surrender to God, only in this view the subject of surrender is another human being. According to Levinas's theory, human rights will return to their original purpose, which is to protect "the others."

\section{CONCLUSIONS}

Human rights are understood as individualistic understandings; there is an argument used to justify human rights that declares every individual has inherent, God-given human rights. As a result, the idea of human rights becomes very difficult to accept. The argument is dogmatic, circular, and tautological. Human rights are not acceptable in civilizations that reject the idea of individualism. In particular, Asia is a civilization that rejects human rights because of their individualistic nature. Asian Values discusses the different values between Asian countries and Western countries. Human rights are considered a Western idea that is trying to be inserted into Asia. It is not only Asian countries that view human rights as individualism; human rights activists and the UDHR itself perpetuate this understanding.

Human rights are not always rejected. The global community, including Asian countries like Indonesia, have at times accepted human rights. Acceptance of human rights may only occur if a subject who feels hurt shouts, "My human rights are violated!" However, one might never defend the human rights of others (especially if they are labeled as the others). Human rights can be used to justify selfish actions. When talking about rights, we rarely ask, "is it good if I do this," but instead point to the rights we have, insisting, "I have the right to..." This condition is exacerbated by the communal culture that has developed in many societies, particularly in Asian societies such as Indonesia. Groups may claim their own rights even as they are hostile to minority groups that are considered disturbing. Acts of violating the rights of minority groups by the majority group may not be considered as wrongdoing due to the understanding that "they" (the minority groups) are wrong, disturbing, and deserving of punishment.

Human rights should be viewed through the lens of Emmanuel Levinas's ethics and existentialism. Levinas was able to explain how humans are basically selfish and fall into "totality." When this "totality" is equated with Hobbes and Locke's theory of the natural human state, it follows that the natural state of humans is "totality." However, "I" experience existential experiences that strive to identify "I" continuously. Identification is done by being aware of separations from "the other." This awareness brings "me" to an encounter with "the other." This "I" who experiences "the other" ultimately feels a responsibility for the other because "I" not only understands the other, but experiences the other. This is how human rights should work - that is, "I" take responsibility for "others" without expecting anything in return.

\section{ACKNOWLEDGMENT}

I want to thank my co-author James Farlow Mendrofa for introducing me to Emmanuel Levinas's theory so my very crude and raw ideas about human rights issues finally found a strong foundation. In addition, my writing is greatly influenced by Alex Lanur's article "Interpersonal Relationship According to Emmanuel Levinas." Lanur's article is very deep but also very straightforward in examining Levinas thoughts.

\section{REFERENCES}

[1] Donnelly, Jack. 1982. Human Rights and Human Dignity: An Analytic Critique of Non-Western Conceptions of Human Rights. Hlmn. 303-316. American Political Science Association. (https://www.jstor.org/stable/1961111, retrieved on 01 May 2019 21:15 UTC)

[2] Sen, Amartya. 1997. Human Rights and Asian Values. USA: Sixteenth Morgenthau Memorial Lecture.

[3] Bedau, Hugo Adam. 2000. “Anarchical Fallacies”: Bentham's Attack on Human Rights. Hlm. 261-279. The Johns Hopkins University Press. (https://www.jstor.org/stable/4489273 retrieved on 25-09-2018 05:22 UTC)

[4] United Nations General Assembly. 1948. Universal Declaration of Human Rights. resolution 217 A (III). Paris: United Nations.

[5] Lanur, Alex. Interpersonal Relation According to Emmanuel Levinas. University of Santo Thomas Gradute School.

[6] Lanur, Alex. 1983. Hubungan antarpribadi menurut Emmanuel Levinas: Representing Representation. Dalam Poespowardojo,

[7] Aquinas, St. Thomas. 1915. Summa Theologica: Representing Representation. in Hayden, Patrick. The philosophy of Human rights. 2001. Hlm. 43-47. United State: Paragon House.

[8] BHP UMY. 2017. Ajaran HAM versi Amerika Serikat Merupakan Bagian dari Sekularisme (The United States version of human rights teachings is part of secularism). Universitas Muhammadiyah Yogyakarta. (http://www.umy.ac.id/ajaran-ham-versi-amerika-serikatmerupakan-bagian-dari-sekularisme.html, retrieved on 26 February 2019) 
[9] Cranston, Maurice. 1983. Are There Any Human Rights?. Daedalus, Vol. 112, No. 4, Human Rights, pp. 1-17. The MIT Press on behalf of American Academy of Arts \& Sciences. (https://www.jstor.org/stable/20024883, retrieved on 13-10-2018 17:52 UTC)

[10] Dwiyanto, Agus. Kusumasari, Bevaola. 2001. Paternalism in Public Service Bureaucracya. PB No. 02 2001. Comparative Research Project on Rural Public Service and Local-Level Civil Service Reforms. Yogyakarta: Universitas Gajah Mada.

[11] Grotius, Hugo. 1901. The Rights of War and Peace: Representing Representation. in Hayden, Patrick. The philosophy of Human rights. 2001. Hlm. 48-54. United State: Paragon House.

[12] Heyden, Patrick. 2001. The Philosophy of Human Right. United States: Paragon House.
[13] Hobbes, Thomas. 1839. Leviathan: Representing Representation. in Hayden, Patrick. The philosophy of Human rights. 2001. Hlm. 58-70. United State: Paragon House.

[14] Soerjanto; Bertens, K. Sekitar Manausia: Bunga Rampai Tentang Filsafat Manusia (Around Humans: Collection of Articles About Human Philosophy). Hlm. 58-70. Jakarta: PT Gramedia.

[15] Robet, Robertus. Primaldhi, Alfindra. 2019. Kultur HAM di Indonesia (Hasil Survey) (Human Rights Culture in Indonesia (Survey Results)). Published in hakasi.id. (http://hakasasi.id/article/detail/111?name=Kultur+HAM+di+Indones ia $+2019+\% 28$ Hasil+Survei\%29, retrieved on 14 April 2019)

[16] Sung-Joo, Han. Asian Values : Asset or Liability. South Korea : Ilmin International Relations Institute Korea University 